\title{
CLASSIFIED CONSTRUCTION OF GENERALIZED FURUTA TYPE OPERATOR FUNCTIONS, II
}

\author{
JIANGTAO YUAN
}

Abstract. As a continuation of our previous work with the same title, the construction of grand Furuta inequality (GFI) is improved in order to give a constructive proof of Uchiyama's result (2003). Afterwards the generalization of Uchiyama's result is obtained by mathematical induction which implies Furuta's recent results.

Mathematics subject classification (2010): 47A63, 47B15, 47B65.

Keywords and phrases: Positive operator, Löwner-Heinz inequality, Furuta inequality, operator functions.

\section{REFERENCES}

[1] A. Aluthge, On p-hyponormal operators for $0<p<1$, Integral Equations Operator Theory, 13 (1990), 307-315.

[2] T. Ando AND F. HiaI, Log majorization and complementary Golded-Thompson type inequality, Linear Algebra Appl., 197 (1994), 113-131.

[3] N. Bebiano, R. Lemos And J. Providê ncia, Inequalities for quantum relative entropy, Linear Algebra Appl., 401 (2005), 159-172.

[4] N. N. Chan AND M. K. Kwong, Hermitian matrix inequalities and a conjecture, Amer. Math. Monthly, 92 (1985), 533-541.

[5] M. FuJII, Furuta's inequality and its mean theoretic approach, J. Operator Theory, 23 (1990), $67-$ 72.

[6] M. FujiI, J. F. JiAng And E. KAMEI, A geometrical structure in the Furuta's inequality, II, Nihonkai Math. J., 8 (1997), 37-46.

[7] M. Fuji And E. KameI, Mean theoretic approach to the grand Furuta inequality, Proc. Amer. Math. Soc., 124 (1996), 2751-2756.

[8] M. Fuji, E. Kamei And R. NaKamoto, Grand Furuta inequality and its variant, J. Math. Inequal., 1, 3 (2007), 437-441.

[9] M. Fujil, A. MATSUMOto AND R. NAKAмото, A short proof of the best possibility for the grand Furuta inequality, J. Inequal. Appl., 4 (1999), 339-344.

[10] M. FujiI, R. NAKAmoto And M. TominaGa, Genaralized Bebiano-Lemos-Providência inequalities and their reverses, Linear Algebra Appl., 426 (2007), 33-39.

[11] T. FURUTA, $A \geqslant B \geqslant 0$ assures $\left(B^{r} A^{p} B^{r}\right)^{1 / q} \geqslant B^{\frac{p+2 r}{q}}$ for $r \geqslant 0, p \geqslant 0, q \geqslant 1$ with $(1+2 r) q \geqslant$ $p+2 r$, Proc. Amer. Math. Soc., 101 (1987), 85-88.

[12] T. FuRUTA, Elementary proof of an order preserving inequality, Proc. Japan Acad. Ser. A Math. Sci., 65 (1989), 126.

[13] T. FurUtA, Two operator functions with monotone property, Proc. Amer. Math. Soc., 111 (1991), 511-516.

[14] T. FURUTA, Extension of the Furuta inequality and Ando-Hiai log-majorization, Linear Algebra Appl., 219 (1995), 139-155.

[15] T. FURUTA, Simplified proof of an order preserving operator inequality, Proc. Japan Acad. Ser. A Math. Sci., 74 (1998), 114.

[16] T. FurutA, A proof of an order preserving inequality, Proc. Japan Acad. Ser. A Math. Sci., 78 (2002), 26. 
[17] T. FURUTA, Operator inequality implying generalized Bebiano-Lemos-Providência one, Linear Algebra Appl., 426 (2007), 342-348.

[18] T. FURUTA, Monotonicity of order preserving operator functions, Linear Algebra Appl., 428 (2008), 1072-1082.

[19] T. FURUTA, Further extension of an order preserving operator inequality, J. Math. Inequal., 2, 4 (2008), 465-472.

[20] T. FuRUTA, Invitation to Linear Operators -From Matrices to Bounded Linear Operators on a Hilbert Space, Taylor \& Francis, London, 2001.

[21] F. HANSEN AND G. K. PEDERSEN, Jensen's inequality for operators and Lö wner's theorem, Math. Ann., 258 (1982), 229-241.

[22] M. ITO AND E. KAMEI, A complement to monotonicity of generalized Furuta-type operator functions, Linear Algebra Appl., 430 (2009), 544-546.

[23] M. ITO AND T. YAMAZAKI, Relations between two inequalities $\left(B^{\frac{r}{2}} A^{p} B^{\frac{r}{2}}\right)^{\frac{r}{p+r}} \geqslant B^{r}$ and $\left(A^{\frac{p}{2}} B^{r} A^{\frac{p}{2}}\right)^{\frac{p}{p+r}} \leqslant A^{p}$ and its applications, Integral Equations Operator Theory, 44 (2002), 442-450.

[24] E. KAMEI, A satellite to Furuta's inequality, Math. Japon., 33 (1988), 883-886.

[25] F. Kubo And T. Ando, Means of positive linear operators, Math. Ann., 246 (1980), $205-224$.

[26] K. TAnAhashi, Best possibility of Furuta inequality, Proc. Amer. Math. Soc., 124 (1996), 141-146.

[27] K. TANAhashi, The Furuta inequality with negative powers, Proc. Amer. Math. Soc., 127 (1999), 1683-1692.

[28] K. Tanahashi, The best possibility of the grand Furuta inequality, Proc. Amer. Math. Soc., 128 (2000), 511-519.

[29] M. UChiYAmA, Criteria for monotonicity of operator mean, J. Math. Soc. Japan, 55, 1 (2003), 197-207.

[30] T. YAMAZAKI, Simplified proof of Tanahashi's result on the best possibility of generalized Furuta inequality, Math. Inequal. Appl., 2 (1999), 473-477.

[31] M. YANAGIDA, Powers of class $w A(s, t)$ operators associated with generalized Aluthge transformation, J. Inequal. Appl., 7, 2 (2002), 143-168.

[32] C. Yang And J. YuAn, On class $w F(p, r, q)$ operators, Acta Math. Sci. Ser. A Chin. Ed., 27, 5 (2007), 769-780.

[33] J. YUAN AND Z. GAO, The Furuta inequality and Furuta type operator functions under chaotic order, Acta Sci. Math. (Szeged), 73 (2007), 669-681.

[34] J. YUAN AND Z. GAO, Structure on powers of p-hyponormal and log-hyponormal operators, Integral Equations Operator Theory, 59 (2007), 437-448.

[35] J. YUAN AND Z. GAO, The operator equation $K^{p}=H^{\frac{\delta}{2}} T^{\frac{1}{2}}\left(T^{\frac{1}{2}} H^{\delta+r} T^{\frac{1}{2}}\right)^{\frac{p-\delta}{\delta+r}} T^{\frac{1}{2}} H^{\frac{\delta}{2}}$ and its applications, J. Math. Anal. Appl., 341 (2008), 870-875.

[36] J. YUAN AND Z. GAO, Classified construction of generalized Furuta type operator functions, Math. Inequal. Appl., 11, 2 (2008), 189-202.

[37] J. YUAn AND Z. GAO, Complete form of Furuta inequality, Proc. Amer. Math. Soc., 136, 8 (2008), 2859-2867. 